Available online on 15.02.2021 at http://jddtonline.info
Oc 2011-21, publisher and licensee JDDT, This is an Open Access article which permits
unrestricted non-commercial use(CC By-NC), provided the original work is properly cited
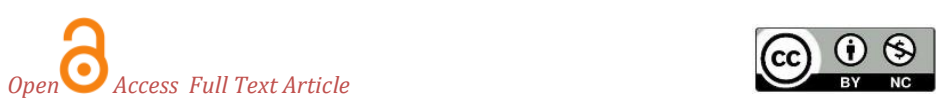

Review Article

\title{
A concise review on preparation methods used for the development of solid lipid nanoparticles
}

\author{
Vasu Deva Reddy Matta \\ Dr. Reddy's Laboratories Ltd., Bachupally, Hyderabad, Telangana State, India
}

\begin{abstract}
Article Info:
Article History:

Received 07 Dec 2020;

Review Completed 13 Jan 2021

Accepted 21 Jan 2021

Available online 15 Feb 2021

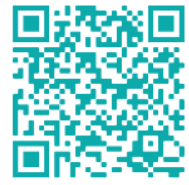

Abstract

*Address for Correspondence:

Vasu deva Reddy Matta, Dr. Reddy's Laboratories Ltd., Bachupally, Hyderabad, Telangana State, India

Solid lipid nanoparticles (SLNs) are in submicron size range nanoparticles and are made of biocompatible and biodegradable materials (mainly composed of lipids and surfactants) capable of incorporating both lipophilic and hydrophilic drugs. SLNs are also considered as substitute to other colloidal drug systems, also used as controlled systems and targeted delivery. SLNs can be considered as an alternative for oral drug delivery vehicle to improve the oral bioavailability of drugs, associated reduction of drug toxicity and stability of drug in both GIT and plasma. There are different techniques used for the preparation of SLNs. Generally, the preparation of SLNs and any other nanoparticle system necessitates a dispersed system as precursor; otherwise particles are produced through the use of a particular instrumentation. This review provides the summary on the techniques or methods used for the development of SLNs of poorly water soluble drugs for improved drug delivery.
\end{abstract}

Keywords: Solid lipid nanoparticles, controlled delivery, precursor, techniques.

\section{Cite this article as:}

Matta VDR, A concise review on preparation methods used for the development of solid lipid nanoparticles, Journal of Drug Delivery and Therapeutics. 2021; 11(1-s):162-169 DOI: http://dx.doi.org/10.22270/jddt.v11i1-s.4687

\section{Introduction}

Administration by the oral route remains most prevalent way of drug delivery. Despite the popularity and versatility of the oral route, significant problems remain. Not all drug molecules possess the physical, chemical or biological characteristics necessary for the successful therapy by oral route ${ }^{1,2}$. Problems such as poor solubility or chemical stability in the location of the gastrointestinal tract, poor permeability over the biological membranes or compassion to metabolism are well known to result in the refusal of potential drug candidates as oral applied products ${ }^{3-8}$. Lipid based drug delivery systems have been proposed as a means of by-passing some of more resistant chemical or physical barriers associated with poorly absorbed drugs ${ }^{9-13}$. Hence, various alternative drug delivery systems are developed to enhance the oral BA of these drugs. The delivery systems include; enhancement of solubility through solid dispersions ${ }^{14}, 15$, liquisolid compacts ${ }^{16}$; avoid first-pass metabolism through buccal delivery or nasal route17-20; increase the stability and prolonged residence time through floating systems ${ }^{21-26}$, increase the mucoadhesive property ${ }^{27}$ 30; lipid based delivery systems for by passing metabolism with solid lipid nanoparticles 31,32 , transfersomes 33,34 , nanostructured lipid carriers ${ }^{35}$ and micronization for reducing particle size using nanosuspensions ${ }^{36-38}$.
Colloidal carrier systems also protect sensitive drugs against the degradation in biological fluids. They offer protection of patient against gastric irritation and can also be the candidate for prolonged drug action due to sustained release. Colloidal particles as drug carriers are also promising candidates for drug targeting ${ }^{39}$. Colloidal carrier systems are mostly based on compositions similar to the physiological structures exhibit greater biological acceptance. Also, lipids are easily metabolized to nontoxic metabolites. Colloidal systems using biodegradable polymers have also been extensively investigated and proved to be ideal candidates for per oral drug administration 40,41 .

Solid lipid nanoparticles (SLNs) are emerging as alternative carriers to colloidal drug systems, for controlled systems and targeted delivery. These are in submicron size range (50$1000 \mathrm{~nm}$ ) and are made of biocompatible and biodegradable materials capable of incorporating lipophilic and hydrophilic drugs. SLNs combine the advantage of different colloidal carriers, for instance, like emulsions and liposomes, these are physiologically acceptable and like polymeric nanoparticles, controlled release of drug from lipid matrix can be anticipated ${ }^{42-44}$.

SLNs are particles made from solid lipids (i.e., lipids solid at room temperature and also at body temperature) and stabilized by surfactant(s). By definition, the lipids can be highly purified triglycerides, complex glyceride mixtures or 
even waxes. Through the work of various research groups, the SLN carrier system has been characterized intensively ${ }^{45}$.

There are different techniques for the preparation of SLNs. Generally, the preparation of any nano carrier system requires a dispersed system as precursor, or else particles are produced through the use of a specific instrumentation. This review mainly provides the insights onto the different production techniques used for the development of SLNs.

\section{Structure of solid lipid nanoparticles}

SLNs consist of a core of solid lipid with the bioactives being a part of the lipid matrix (Figure 1). The particle is stabilized by a surfactant layer, which may consist of a single surfactant, but typically is composed of a mixture of surfactants. In general, the use of crystallized lipids instead of liquid lipids has been shown to increase control over release and stability of incorporated bioactive. This is because mobility of bioactives can be controlled by controlling the physical state of the lipid matrix ${ }^{44}$.

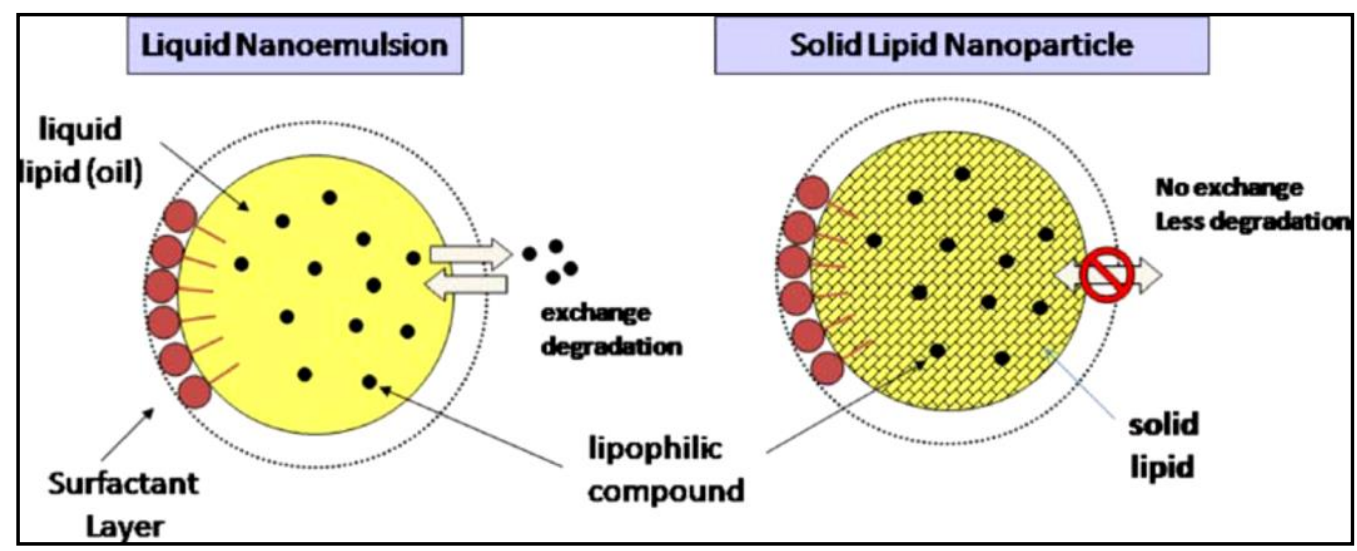

Figure 1: Structure of liquid nanoemulsions (left) and solid lipid nanoparticles (right) stabilized by a surfactant layer carrying a lipophilic bioactive

\section{Preparation methods of SLNs}

Based on the type of precursor and also type of process, SLNs preparation methods are classified as follows: emulsions as precursor, hot homogenization, melt dispersion or film formation technique, phase-inversion temperature method, solvent evaporation-diffusion from emulsions), microemulsions (microemulsion dilution and microemulsion cooling techniques), micellar solutions (coacervation technique). Some preparation techniques are based on supercritical fluids. The most important techniques which involve the use of particular instrumentation are: membrane contactor technique, spray-drying, spray-congealing and electrospray. Different methods used for the production of SLNs mentioned in Table 1.

Table 1: Preparation method of SLNs based on type of precursor and instrumentation used.

\begin{tabular}{|l|l|}
\hline Type of precursor & Method used \\
\hline \multirow{4}{*}{ Precursor as emulsion } & hot homogenization technique \\
\cline { 2 - 2 } & melt dispersion technique \\
\cline { 2 - 2 } & phase-inversion temperature \\
\cline { 2 - 2 } & solvent evaporation-diffusion \\
\cline { 2 - 2 } Precursor as microemulsion & hot homogenization technique \\
\hline Precursor as micellar solutions & microemulsion dilution \\
\cline { 2 - 2 } & microemulsion cooling techniques \\
\hline \multirow{3}{*}{ Use of particular instrumentation } & Coacervation technique \\
\hline & membrane contactor technique, \\
\cline { 2 - 2 } & spray-drying, \\
\cline { 2 - 2 } & spray-congealing \\
\cline { 2 - 2 } & Electrospray. \\
\hline
\end{tabular}




\section{High pressure homogenization (Hot and Cold)}

High pressure homogenization (HPH) has emerged as a reliable and powerful technique for the preparation of SLN. Homogenizers of different sizes are commercially available from several manufacturers. The high pressure homogenization technique has been demonstrated to be the most effective technique due to some advantages such as narrow particle size distribution of the product with a low content of microparticles $(>5 \mu \mathrm{m}$ is requested for iv injections), higher particle content in the dispersions, avoidance of organic solvents, acceptability of the homogenization equipment by the regulatory authorities (even for parenteral products), scale-up feasibility and the availability of homogenization lines in industry ${ }^{46}$. Depending on the size of production-scale homogenizers, a wide production range can be possible ${ }^{47}$. There are two general approaches within the homogenization technique, the hot and the cold homogenization. In both cases, a preparatory step involves the drug incorporation into the bulk lipid by dissolving or dispersing the drug in the lipid melt.

\section{Hot homogenization technique}

Hot homogenization is carried out at temperatures above the melting point of the lipid and can therefore be regarded as the homogenization of an emulsion. Pre-emulsion of the drug loaded lipid melt and the aqueous emulsifier phase (same temperature) is obtained by high-shear mixing device (Ultra-Turrax). The quality of the pre-emulsion affects the quality of the final product to a large extent and it is desirable to obtain droplets in the size range of a few micrometers. HPH of the pre-emulsion is carried out at temperatures above the melting point of the lipid. In general, higher temperatures result in lower particle sizes due to the decreased viscosity of the inner phase. However, high temperatures may also increase the degradation rate of the drug and carrier. The homogenization step can be repeated several times. It should always be kept in mind, that high pressure homogenization increases the temperature of the sample (approximately $10^{\circ} \mathrm{C}$ for 500 bar). In most cases, 3-5 homogenization cycles at 500-1500 bar are sufficient. Increasing the homogenization pressure or the number of cycles often results in an increase of the particle size due to particle coalescence which occurs as a result of the high kinetic energy of the particles ${ }^{48}$.

The primary product of the hot homogenization is a nanoemulsion due to the liquid state of the lipid. Solid particles are expected to be formed by the following cooling of the sample to room temperature or to temperatures below $^{49}$. Due to the small particle size and the presence of emulsifiers, lipid crystallization may be highly retarded and the sample may remain as a supercooled melt for several months.

The hot homogenization technique is also suitable for drugs showing some temperature sensitivity because the exposure to an increased temperature is relatively short. In case of highly temperature-sensitive compounds the cold homogenization technique can be applied.

A camptothecin loaded SLN suspension consisted of $0.1 \%$ $(\mathrm{w} / \mathrm{w})$ camptothecin, $2.0 \%(\mathrm{w} / \mathrm{w})$ stearic acid, $1.5 \%(\mathrm{w} / \mathrm{w})$ soybean lecithin and $0.5 \%(\mathrm{w} / \mathrm{w})$ polyoxyethylenepolyoxypropylene copolymer (Poloxamer 188) was prepared by high pressure homogenization ${ }^{50,51}$.

\section{Cold homogenization technique}

In contrast, the cold homogenization is carried out with the solid lipid and represents, therefore, a high pressure milling of a suspension. Effective temperature control and regulation is needed in order to ensure the un-molten state of the lipid due to the increase in temperature during homogenization. Cold homogenization has been developed to overcome the following three problems of the hot homogenization technique:

\section{- Temperature-induced drug degradation}

- Drug distribution into the aqueous phase during homogenization

- Complexity of the crystallization step of the nanoemulsion leading to several modifications and/or supercooled melts

The first preparatory step is the same as in the hot homogenization procedure and includes the solubilization or dispersing of the drug in the melt of the bulk lipid. However, the following steps are different. The drug containing melt is rapidly cooled (e.g.by means of dry ice or liquid nitrogen). The high cooling rate favors a homogenous distribution of the drug within the lipid matrix. The solid, drug containing lipid is milled to microparticles. Typical particle sizes obtained by means of ball or mortar milling are in the range of 50-100 microns. Low temperatures increase the fragility of the lipid and favor, therefore, particle comminution. The solid-lipid microparticles are dispersed in a chilled emulsifier solution. The pre-suspension is subjected to high pressure homogenization at or below room temperature. In general, compared to hot homogenization, larger particle sizes and a broader size distribution are observed in cold homogenized samples ${ }^{49}$. The method of cold homogenization minimizes the thermal exposure of the sample, but it does not avoid it due to the melting of the lipid /drug-mixture in the initial step.

\section{Microemulsion method}

Addition of a microemulsion to water leads to precipitation of the lipid phase forming fine particles. This effect is exploited in the preparation method for SLN developed by Gasco ${ }^{45}$.

Considering incorporation of shear and temperaturesensitive compounds such as DNA, albumin and erythropoietin, the HPH is not suitable and therefore, other preparation techniques; such as precipitation from microemulsion have been developed. Microemulsions are thermodynamically stable colloid mixtures of two immiscible solvents stabilized by an adsorbed surfactant film at the liquid-liquid interface. They can be prepared spontaneously by mixing surfactant, co surfactant, oil and water. Thus, no energy is required to prepare microemulsion, and the simplest representation of the structure of microemulsion is the droplet model with small droplet diameter, generally below $100 \mathrm{~nm}$. Synthesis of nanoparticles in microemulsions is an area of considerable current interest ${ }^{49}$.

To form a microemulsion with a lipid being solid at room temperature, the microemulsion needs to be produced at a temperature above the melting point of the lipid. The lipid (fatty acids and/or glycerides) is molten, a mixture of water, co-surfactant(s) and the surfactant is heated to the same temperature as the lipid and added under mild stirring to the lipid melt. A transparent, thermodynamically stable system is formed when the compounds are mixed in the correct ratio for microemulsion formation. This microemulsion is then dispersed in a cold aqueous medium $\left(2-3^{\circ} \mathrm{C}\right)$ under mild mechanical mixing, thus ensuring that the small size of the particles is due to the precipitation. Volume ratios of the hot microemulsion to cold water are in the range of 1:25 and 1:50. Rapid recrystallization of oil droplet on dispersion in cold aqueous medium produces SLNs. Surfactants and co- 
surfactants include lecithin, bile salts, but also alcohols such as butanol. Excipients such as butanol are less favorable with respect to regulatory aspects ${ }^{52}$.

\section{Solvent emulsification method}

SLNs have been produced by solvent emulsification technique by Siekmann ${ }^{53}$. Lipid matrix is dissolved in water immiscible organic solvent (chloroform or cyclohexane) that is emulsified in an aqueous phase. Upon evaporation of the solvent, nanoparticle dispersion is formed due to the precipitation of the lipid in the aqueous medium ${ }^{54}$.

The advantage of this procedure over the cold homogenization process described before is the avoidance of any thermal stress. Residues of organic solvents used in this method create toxicity problems and is the major disadvantage of this method.

\section{Solvent diffusion method}

The first step in the production of lipid nanoparticles by the solvent diffusion technique is to prepare a solvent in water emulsion with a partially water miscible solvent containing the lipid. Low toxic, water miscible solvents such as benzyl alcohol or butyl lactate were used. Upon transferring a transient oil-in-water emulsion into water and continuous stirring, droplets of dispersed phase solidify as lipid nanoparticles due to diffusion of the organic solvent 55 .

\section{Double emulsion method}

Recently, a novel method based on solvent emulsificationevaporation for the preparation of SLN loaded with hydrophilic drugs has been introduced. Here, the hydrophilic drug is encapsulated along with a stabilizer to prevent drug partitioning to the external water phase during solvent evaporation in the internal water phase of a w/o/w double emulsion. In double emulsion technique, the drug was dissolved in aqueous solution, and then was emulsified in melted lipid. This primary emulsion was stabilized by adding stabilizer (e.g. gelatin, poloxamer-407). Then this stabilized primary emulsion was dispersed in aqueous phase containing hydrophilic emulsifier ${ }^{56}$. Thereafter, the double emulsion was stirred and was isolated by filtration. Double emulsion technique avoids the necessity to melt the lipid for the preparation of peptide-loaded lipid nanoparticles and the surface of the nanoparticles could be modified in order to sterically stabilize them by means of the incorporation of a lipid/-PEG derivative. Sterical stabilization significantly improved the resistance of these colloidal systems in the gastrointestinal fluids.

This technique is mainly used to encapsulate hydrophilic drug (peptides). A major drawback of this technique is the formation of high percentage of microparticles. SLNs loaded with insulin-mixed micelles (Ins-MMs) were prepared by a novel reverse micelle-double emulsion method, in which sodium cholate and soybean phosphatidylcholine were employed to improve the lipid solubility of insulin, and the mixture of stearic acid and palmitic acid were employed to prepare insulin loaded solid lipid nanoparticles. Some of the formulation parameters were optimized to obtain high quality nanoparticles. The particle size, zeta potential, entrapment efficiency (EE \%) and drug loading capacity (DL $\%$ ) were $114.7 \pm 4.68 \mathrm{~nm},-51.36 \pm 2.04 \mathrm{mV}, 97.78 \pm 0.37 \%$ and $18.92 \pm 0.07 \%$, respectively 5 .

\section{Homogenization followed by Ultra sonication}

It is a simple, sensitive and reproducible method used to prepare SLNs. In brief, drug, lipid, and emulsifier were dissolved in a common solvent and evaporated under reduced temperature to obtain solvent free drug dissolved or dispersed lipid phase. Drug loaded lipid melt was homogenized with hot aqueous surfactant in solution using homogenizer to get coarse emulsion. The coarse emulsion so obtained was ultrasonicated using ultrasonicator to obtain nanoemulsion. SLNs are formed upon cooling to room temperature ${ }^{58-63}$.

\section{Solvent injection method}

The basic principle for the formation of SLNs is similar to the solvent diffusion method. However, SLNs are prepared by rapidly injecting a solution of solid lipids in water miscible solvents into water. Mixture of water miscible solvents can be used to solubilize solid lipids. Normally used solvents in this method are acetone, ethanol, isopropanol, and methanol 64 .

\section{Other methods}

\section{Supercritical fluid}

This is new technique for preparation of SLN giving the advantage of solvent less processing. SLN can be produced by the rapid expansion of supercritical carbon dioxide solutions. Carbon dioxide with $99.99 \%$ is good solvent for preparation of SLN by this method 65 .

\section{Membrane contactor method}

This is a new method of preparation of SLN using a membrane contactor. The lipid phase is pressed, at a temperature above the melting point of the lipid, through the membrane pores allowing the formation of small droplets and the aqueous phase circulates inside the membrane module, and sweeps away the droplets forming at the pore outlets. SLNs are formed by the following cooling of the preparation to room temperature.

In this method different process parameters (aqueous phase and lipid phase temperatures, aqueous phase cross-flow velocity and lipid phase pressure, membrane pore size) influence the size of SLNs ${ }^{66}$.

\section{Co-flowing microchannel technique}

Zhang et al. research group investigated a new method of production of SLNs in a co-flowing microchannel. The microchannel system assembled with inner and outer capillaries. A lipid-solvent phase obtained by dissolving lipid in a water-miscible solvent is injected into the inner capillary, while an aqueous phase with surfactant is injected into the outer capillary at the same time. When these two fluids meet in the outer capillary, the solvent in the lipid phase diffuses rapidly into the aqueous phase, resulting in the local supersaturation of lipid and finally formation of SLNs. This is a simple and easy approach to produce SLNs with small diameters and slight narrow size distribution ${ }^{67}$. The particle diameter was influenced by several factors, the velocities of the lipid-solvent and the aqueous phases, the lipid concentration and the surfactant concentration. Some of the drugs loaded into SLNs using different methods showed in Table 2 and 3. 
Table 2: Different methods of preparation and drugs investigated

\begin{tabular}{|c|c|}
\hline Method of preparation & Drugs investigated \\
\hline Hot homoginization technique & $\begin{array}{l}\text { All trans retinol } \\
\text { Ibuprofen } \\
\text { Camptothecin } \\
\text { Dexamethasone } \\
\text { Ketaconazole } \\
\text { Alpha lipoic acid } \\
\text { Beta carotene } \\
\text { Daidzein } \\
\text { Paclitaxel } \\
\text { Diclofenac sodium } \\
\text { Clotrimazole }\end{array}$ \\
\hline Cold homoginization technique & $\begin{array}{l}\text { Vinorelbine bitartarate } \\
\text { Prednisolone }\end{array}$ \\
\hline Microemulsion technique & $\begin{array}{l}\text { Tobromycin } \\
\text { Idarubicin } \\
\text { Tamoxifen } \\
\text { Curcuminoid } \\
\text { Tea polyphenols } \\
\text { Cyclosporine A } \\
\text { Doxorubicin, Cisplatin } \\
\text { Atazanavir Sulphate }\end{array}$ \\
\hline Solvent emulsification method & $\begin{array}{l}\text { Vinpocitins } \\
\text { Tashinone 2A }\end{array}$ \\
\hline Solvent diffusion method & $\begin{array}{l}\text { Adefovir } \\
\text { Paclitaxel } \\
\text { Clobetasol propionate, Peptide(Gonodorelin) }\end{array}$ \\
\hline Homogenization followed by sonication & $\begin{array}{l}\text { Clozapine } \\
\text { Lovastatin } \\
\text { Nitrendipine }\end{array}$ \\
\hline (W/o/w) double emulsion method & Insulin \\
\hline
\end{tabular}


Table 3: Various SLNs formulations studied by different researcher to improve the oral bioavailability of drugs

\begin{tabular}{|c|c|c|c|}
\hline Drug & Method used & Inference & Ref \\
\hline Adefovir dipivoxil & solvent injection & Improved oral BA & 68 \\
\hline Arteether & $\mathrm{HPH}$ & Improved oral BA & 69 \\
\hline Baicalin & Coacervation & Enhanced bioavailability & 70 \\
\hline Capecitabine & HH-US & Improved BA and tumor targeting & 71 \\
\hline Carvedilol & Microemulsion & Improved BA & 72 \\
\hline Felodipine & HH-US & Improved BA & 73 \\
\hline Isradipine & HH-US & Improved BA & 74 \\
\hline Idarubicin & Microemulsion & Improved BA, modifies the PK and tissue distribution & 75 \\
\hline Ketoconazole & HH-US & Improved BA & 76 \\
\hline Lacidipine & HH-US & Improved oral BA & 77 \\
\hline Methotrexate & Solvent diffusion method & improved BA & 78 \\
\hline Nimodipine & $\mathrm{HPH}$ & Enhanced bioavailability & 79 \\
\hline Nisoldipine & HH-US & Improved BA & 80 \\
\hline Nisoldipine & HH-US & Improved BA & 81 \\
\hline Peptides/proteins & Cold homogenization & Improved stability and permeability & 82 \\
\hline Puerarin & Solvent injection method & Improved BA & 83 \\
\hline Quercetine & Emulsification-solidification & SLNs are carrier to enhance the absorption & 84 \\
\hline $\begin{array}{l}\text { Rifampicin, Isoniazid } \\
\text { and Pyrazinamide }\end{array}$ & $\begin{array}{l}\text { Emulsion-solvent } \\
\text { diffusion }\end{array}$ & Improved BA and stability, Reducing dosing frequency & 85 \\
\hline Rosuvastatin calcium & HH-US & Improved BA & 86 \\
\hline Rosuvastatin calcium & HH-US & Improved BA & 87 \\
\hline Ropinirole & HH-US & Improved BA and brain delivery & 88 \\
\hline $\begin{array}{l}\text { Raloxifene } \\
\text { hydrochloride }\end{array}$ & $\begin{array}{l}\text { Solvent } \\
\text { emulsification/evaporation }\end{array}$ & Bioavailability enhanced & 89 \\
\hline Simvastatin & Solvent injection & Improved BA & 90 \\
\hline Tobramycin & Microemulsion & Improved BA, sustained drug release, lymphatic Targeting & 91 \\
\hline Vinpocetine & $\begin{array}{l}\text { Ultrasonic-solvent } \\
\text { emulsification }\end{array}$ & $\begin{array}{l}\text { Improved oral BA by increased saturated solubility and } \\
\text { reduced metabolism }\end{array}$ & 92 \\
\hline Zaleplone & HH-US & Improved BA & 93 \\
\hline
\end{tabular}

\section{Conclusion}

Different methods have been industrialized for the fabrication of SLNs with the possibility to obtain different size and shape. The size of the SLNs can affect the pharmacological properties of the particles, but it is not the unique parameter considered to compare the various techniques. From a technological point of view, the opportunity to scale-up the process is very vital, but also the viability of the method is appropriate, in fact, the usage of expensive and complex machine can obstruct the production on large scale manner.

\section{References}

1. Fasano A. Innovative strategies for the oral delivery of drugs and peptides. Trends in biotechnology. 1998 Apr 1; 16(4):152-7.

2. Doodipala R. A review of novel formulation strategies to enhance oral delivery of zaleplon. J Bioequvi avail. 2016; 8(5): 211-213.

3. Rajitha R, Narendar D, Arjun N, Mahipal D and Nagaraj B. Colon delivery of naproxen: preparation, characterization and in vivo evaluation. IJPSN, 2016; 9(3), 1-10.

4. Plapied L, Duhem N, des Rieux A, Préat V. Fate of polymeric nanocarriers for oral drug delivery. Current opinion in colloid \& interface science. 2011 Jun 1; 16(3):228-37.

5. Alekya T, Narendar D, Mahipal D, Arjun N, Nagaraj B. Design and evaluation of chronomodulated drug delivery of tramadol hydrochloride. Drug research. 2018 Mar; 68(03):174-80.

6. Thanki K, Gangwal RP, Sangamwar AT, Jain S. Oral delivery of anticancer drugs: challenges and opportunities. Journal of controlled release. 2013 Aug 28; 170(1):15-40.

7. Narendar D, Arjun N, Sunitha K, Harika K, Nagaraj B. Development of osmotically controlled oral drug delivery systems of tramadol hydrochloride: effect of formulation variables on in-vitro release kinetics. Asian J Pharm. 2016; 10(3): 1-10.

8. Arjun N, Narendar D, Sunitha K, Harika K, Madhusudan Rao Y and Nagaraj B. Development, evaluation and influence of formulation and process variables on in vitro performance of oral elementary osmotic device of atenolol. Int J Pharm Invest, 2016; 6(4):1-9.

9. Andrew J. Humberstone, William N. Charman. Lipid-based vehicles for the oral delivery of poorly water soluble drugs. Advanced Drug Delivery Reviews 1997; 25:103-128.

10. Dudhipala N. Influence of Solid Lipid Nanoparticles on Pharmacodynamic Activity of Poorly Oral Bioavailable Drugs. International Journal of Pharmaceutical Sciences and Nanotechnology. 2020 Jul $11 ; 13(4): 4979-83$.

11. Damgé C., Michel C., Aprahamian M. Nanocapsules as carriers for oral peptide delivery. Journal of Controlled Release, 1990; 13:233239.

12. Narendar D and Kishan V. Candesartan cilexetil nanoparticles for improved oral bioavailability. Ther deli, 2017; 8(2):79-88.

13. Florence AT. The oral absorption of micro-and nanoparticulates: neither exceptional nor unusual. Pharm Res 1997; 14:259-66.

14. Ettireddy $S$, Dudhipala $N$. Influence of $\beta$-Cyclodextrin and Hydroxypropyl- $\beta$-Cyclodextrin on Enhancement of Solubility and Dissolution of Isradipine. Int J Pharma Sci and Nanotech. 2017; 10(3):3752-7.

15. Palem CR, Reddy ND, Satyanarayana G, Varsha BP. Development and optimization of Atorvastatin calcium-cyclodextrin inclusion complexed oral disintegrating tablets for enhancement of solubility, dissolution, pharmacokinetic and pharmacodynamic activity by central composite design. Int J Pharm Sci Nanotech 2016; 9(2): 1-11.

16. Butreddy A, Narendar D. Enhancement of solubility and dissolution rate of trandolapril sustained release matrix tablets by liquisolid compact approach. Asian J Pharm 2015; 9 (4): 290-297. 
17. Chinna Reddy Palem, Ramesh Gannu, Narender D, Vamshi Vishnu Yamsani, and Madhusudan Rao Yamsani. Transmucosal Delivery of Domperidone from Bilayered Buccal Patches: In Vitro, Ex Vivo and In Vivo Characterization. Arch Pharm Res. 2011; 34(10):17011710.

18. Chinna Reddy Palem, Narendar D, Sunil Kumar Battu, Michael A. Repka and Madhusudan Rao Yamsani. Development, Optimization and in vivo Characterization of Domperidone Controlled Release Hot Melt Extruded Films for Buccal Delivery. Drug Dev Ind Pharm, 2016; 42(3):473-484.

19. Chinna Reddy Palem, Narendar D, Sunil Kumar Battu, Satyanarayana Goda, and Madhusudan Rao Yamsani. Combined dosage form of pioglitazone and felodipine as mucoadhesive pellets via hot melt extrusion for improved buccal delivery with application of quality by design approach. J Drug Del Sci Tech. 2015; 30:209-219.

20. Dudhipala N, Narala A, Bomma R. Recent Updates in the Formulation Strategies to Enhance the Bioavailability of Drugs Administered via Intranasal Route. J bioequ avail. 2016; 8(5):204207.

21. Reddy, N.D., Chinna R. P., Sunil, R., \& \& Madhusudan, R. Y. Development of floating matrix tablets of Ofloxacin and Ornidazole in combined dosage form: in vitro and in vivo evaluation in healthy human volunteers. Int J Drug Deli, 2012; 4:462-469.

22. Reddy AB, Reddy ND. Development of multiple-unit floating drug delivery system of clarithromycin: formulation, in vitro dissolution by modified dissolution apparatus, in vivo radiographic studies in human volunteers. Drug research. 2017 Jul; 67(07):412-8.

23. Dudipala R, Palem, C.R., Reddy, S., \& Rao, Y.M. Pharmaceutica development and clinical pharmacokinetic evaluation of gastroretentive floating matrix tablets of levofloxacin. Int J Pharma Sci and Nanotech, 2011; 4(3):1461-1467.

24. Narendar D, K. Someshwar, N. Arjun and Y. Madhusudan Rao. Quality by design approach for development and optimization of Quetiapine Fumarate effervescent floating matrix tablets for improved oral delivery. J Pharm Investigation., 2016; 46(3):253263.

25. Donthi MR, Dudhipala NR, Komalla DR, Suram D, Banala N. Preparation and Evaluation of Fixed Combination of Ketoprofen Enteric Coated and Famotidine Floating Mini Tablets by Single Unit Encapsulation System. Journal of Bioequivalence \& Bioavailability. 2015; 7(6):279.

26. Donthi MR, Dudipala N, Komalla DR, Suram D, Banala N. Design and Evaluation of Floating Multi Unit Mini Tablets (MUMTS) Muco Adhesive Drug Delivery System of Famotidine to Treat Upper Gastro Intestinal Ulcers. Journal of Pharmacovigilance. 2015 Oct 12.

27. Banala N, Peddapalli H, Dudhipala N, Chinnala KM. Transmucosal Delivery of Duloxetine Hydrochloride for Prolonged Release: Preparation, in vitro, ex vivo Characteri-zation and in vitro-ex vivo Correlation. International Journal of Pharmaceutical Sciences and Nanotechnology. 2018 Sep 30; 11(5):4249-58.

28. Narendar D, Arjun N, Karthik Yadav J and Ramesh Bomma Amoxycillin Trihydrate Floating-Bioadhesive Drug Delivery System for Eradication of Helicobacter pylori: Preparation, In Vitro and Ex Vivo Evaluation. J bioequ avail. 2016; 8(3):118-124.

29. Nagaraj B, Anusha K, Narendar D, Sushma P. Formulation and evaluation of microemulsion-based transdermal delivery of duloxetine hydrochloride. International Journal of Pharmaceutical Sciences and Nanotechnology. 2020 Jan 31; 13(1):4773-82.

30. Shruthi K, Narendar D, Arjun N, Kishan V. Development and Antimicrobial Evaluation of Binary Ethosomal Topical Gel of Terbinafine Hydrochloride for the Treatment of Onychomycosis. Int. J. Pharm. Sci. Nanotechnol. 2018; 11:3998-4005.

31. $\mathrm{Hu}$ FQ, Jiang SP, Du YZ, et al. Preparation and characterization of stearic acid nanostructured lipid carriers by solvent diffusion method in an aqueous system. Coll Surf B: Biointerf, 2005; 45:16773.

32. Vamshi Krishna M, Vijay Kumar B, Narendar Dudhipala. In-situ Intestinal Absorption and Pharmacokinetic Investigations of Carvedilol Loaded Supersaturated Self-Emulsifying Drug System. Pharm Nanotechnol. 2020 May 17. doi: $10.2174 / 2211738508666200517121637$.

33. Pitta S, Dudhipala N, Narala A and Veerabrahma K. Development and evaluation of zolmitriptan transfersomes by Box-Behnken design for improved bioavailability by nasal delivery. Drug Dev Ind Pharm. 2018; 44(3):484-492.
34. Narendar D, Riyaz PMD, Ahmed AY, Nagaraj B. Effect of lipid and edge activator concentration on development of Aceclofenac loaded transfersomes gel for transdermal application: in vitro and ex vivo skin permeation. Dru Dev Ind Pharm. 2020; 46(8):13341344.

5. Tirumalesh C, Suram, D.; Dudhipala, N.; Banala, N. Enhanced pharmacokinetic activity of Zotepine via nanostructured lipid carrier system in Wistar rats for oral application. Pharm. Nanotechnol. 2020, 8(2):158-160.

36. Karri V, Butreddy A, Narender R. Fabrication of Efavirenz Freeze Dried Nanocrystals: Formulation, Physicochemical Characterization, In Vitro and Ex Vivo Evaluation. Advanced Science, Engineering and Medicine. 2015; 7(5): 385-392.

37. K. Nagaraj, D. Narendar and V. Kishan. Development of olmesartan medoxomil optimized nanosuspension using the Box-Behnken design to improve oral bioavailability. Drug Dev Ind Pharm, 2017; 43(7):1186-1196.

38. Butreddy A, Narala A, Dudhipala N. Formulation and characterization of Liquid Crystalline Hydrogel of Agomelatin: In vitro and Ex vivo evaluation. Journal of Applied Pharmaceutical Science. 2015 Sep; 5(09):110-4.

39. Müller RH. Colloidal carriers for controlled drug delivery and targeting: Modification, characterization and in vivo distribution. Taylor \& Francis; 1991

40. Bugnicourt L, Ladavière C. A close collaboration of chitosan with lipid colloidal carriers for drug delivery applications. Journal of Controlled Release. 2017 Jun 28; 256:121-40.

41. Barratt G. Colloidal drug carriers: achievements and perspectives. Cellular and Molecular Life Sciences CMLS. 2003 Jan 1; 60(1):2137.

42. Müller R.H., Mehnert W., Lucks J.S., Schwarz .C, ZurMühlen A., Weyhers H., Freitas C., Ruhl D. Solid lipid nanoparticles (SLN)-An alternative colloidal carrier system for controlled drug delivery. European Journal of Pharmaceutics and Biopharmaceutics, 1995; 41:62-69.

43. Mehnert, W., Mäder, K. (2001). Solid lipid nanoparticles production, characterization and applications. Adv Drug Deliv Rev. 47:165-196.

44. Dudhipala N. A Comprehensive Review on Solid Lipid Nanoparticles as Delivery Vehicle for Enhanced Pharmacokinetic and Pharmacodynamic Activity of Poorly Soluble Drugs. Int J Pharm Sci Nanotech. 2019; 12:4421-40.

45. M.R. Gasco, Method for producing solid lipid microspheres having a narrow size distribution. United States Patent, 1993, USS 188837.

46. Gohla SH, Dingler A. Scaling up feasibility of the production of solid lipid nanoparticles (SLN ${ }^{\mathrm{TM}}$ ). Pharmazie, 2001; 56:61-3.

47. Müller RH, Keck CM. Challenges and solutions for the delivery of biotech drugs - a review of drug nanocrystal technology and lipid nanoparticles. J Biotech, 2004; 113:151-70.

48. Arun Butreddy, Narendar Dudhipala and Kishan Veerabrahma Development of olmesartanmedoxomil lipid based nanoparticles and nanosuspension: Preparation, characterization and comparative pharmacokinetic evaluation. Artificial cells, nanomed and biotech, 2018; 46(1):126-137.

49. Mehnert, W., Mäder, K. Solid lipid nanoparticles production, characterization and applications. Adv Drug Deliv Rev. 2012; 64:83-101.

50. Yang S, Zhu J, Lu Y, et al. Body distribution of camptothecin solid lipid nanoparticles after oral administration. Pharm Res, 1999b; 16:751-57.

51. Yang S, Zhu J, Lu Y, et al. Body distribution of camptothecin solid lipid nanoparticles after oral administration. Pharm Res, 1999b; 16:751-57.

52. Müller, R.H., Mäder, K., Gohla, S. Solid lipid nanoparticles (SLN) for controlled drug delivery a review of the state of the art. Eur J Pharm Biopharm. 2000; 50:161-177.

53. Siekmann B, Westesen K. Submicron-sized parenteral carrier systems based on solid lipids. Pharm Pharmacol Lett, 1992; 1:1236.

54. Sjostrom B, Bergenstahl B. Preparation of submicron drug particles in lecithin-stabilized o/w emulsions I. Model studies of the precipitation of cholesterylacetate. Int J Pharm, 1992; 88:5362 .

55. Schubert MA, Muller-Goyman CC. Solvent injection as a new approach for manufacturing lipid nanoparticles - evaluation of the method and process parameters. Eur J Pharm Biopharm, 2003; 55:125-31. 
56. Zimmermann E, Muller RH. Electrolyte- and pH-stabilities of aqueous solid lipid nanoparticle (SLNTM) dispersions in artificial gastrointestinal media. Eur J Pharm Biopharm, 2001; 52:203-10.

57. Liu et al, Solid lipid nanopartiles for pulmonary delivery of insulin. Int J Pharm, 2008; 356:333-344.

58. Dudhipala N, Veerabrahma K. Candesartan cilexetil loaded solid lipid nanoparticles for oral delivery: characterization, pharmacokinetic and pharmacodynamic evaluation. Drug delivery. 2016 Feb 12; 23(2):395-404

59. Akshaya Tatke, Narendar Dudhipala, Karthik Yadav Janga, Sai Prachetan Balguri, BharathiAvula, Monica M. Jablonski Soumyajit Majumdar. In Situ Gel of Triamcinolone Acetonide-Loaded Solid Lipid Nanoparticles for Improved Topical Ocular Delivery: Tear Kinetics and Ocular Disposition Studies. Nanomaterials (Basel). 2018 Dec 27; 9(1). pii: E33. doi: 10.3390/nano9010033.

60. Ahmed AAY, Narendar D, Mujumdar S. Ciprofloxacin Loaded Nanostructured Lipid Carriers Incorporated into In-Situ Gels to Improve Management of Bacterial Endophthalmitis. Pharmaceutics, 2020; 12(6):572.

61. Dudhipala Narendar, and Ahmed Adel Ay. Amelioration of ketoconazole in lipid nanoparticles for enhanced antifungal activity and bioavailability through oral administration for management of fungal infections. Chemistry and Physics of Lipids 2020; 232:104953.

62. Banala, N, Tirumalesh C, Suram, D. Dudhipala, N. Zotepine loaded lipid nanoparticles for oral delivery: preparation, characterization, and in vivo pharmacokinetic studies. Fut J Pharm Sci, 2020; $6(1): 37$

63. Banala N, Cernam T, Suram D, Dudhipala N. Design, development and in vivo pharmacokinetic evaluation of zotepine loaded solid lipid nanoparticles for enhanced oral bioavailability. ACTA Pharmaceutica Sciencia.

64. Schubert MA, Harms M, Muller-Goyman CC. Sructural investigations on lipid nanoparticles containing high amounts of lecithin. Eur J Pharm Sci, 2006; 27:226-36.

65. Trucillo P, Campardelli R. Production of solid lipid nanoparticles with a supercritical fluid assisted process. The Journal of Supercritical Fluids. 2019 Jan 1; 143:16-23.

66. Charcosset C, Assma Ahmed El-Harati, Hatem Fessi, A membrane contactor for the preparation of solid lipid nanoparticles. Desalination, 2006; 200:570-571.

67. Zhang S.H., Shen S.C., Chen Z., Yun J.X. Preparation of solid lipid nanoparticles in co-flowing microchannels. Chemical Engineering Journal, 2008; 144: 324-328.

68. Dodiya S, Sandip, Chavhan., Aruna, Korde., \&Krutika, K. Sawant. Solid lipid nanoparticles and nanosuspension of adefovirdipivoxil for bioavailability improvement: formulation, characterization, pharmacokinetic and biodistribution studies. Drug. Dev. Ind. Pharm., 2013; 39(5):733-743.

69. Dwivedi P, Khatik R, Khandelwal K, Taneja I, Rama Raju KS, Wahajuddin, Paliwal SK, Dwivedi AK, Mishra PR. Pharmacokinetics study of arteether loaded solid lipid nanoparticles: An improved oral bioavailability in rats. International Journal of Pharmaceutics 2014; 466:321-327.

70. Hao, J., Wang, F., Wang, X., Zhang, D., YBi, Y., Gao, Y., Zhao, X., \&amp; Zhang, Q. Development and optimization of baicalin-loaded solid lipid nanoparticles prepared by coacervation method using central composite design. Eur. J. Phar. Sci., 2012; 47:497-505.

71. Narendar D, Govardhan K. Capecitabine lipid nanoparticles for anti-colon cancer activity in 1, 2-dimethylhydrazine induced colon cancer: Preparation, cytotoxic, pharmacokinetic and pathological evaluation. Drug dev Ind pharm, Eraly online, March 2018. doi: 10.1080/03639045.2018.1445264.

72. Sanjula B. Effect of poloxamer 188 on lymphatic uptake of carvedilol-loaded solid lipid nanoparticles for bioavailability enhancement. J Drug Target 2009; 17:249-56.

73. Usha Kiranmai G, Narendar Dudhipala and Veerabrahma Kishan Preparation, characterization and in vivo evaluation of felodipine solid lipid nanoparticles to improve the oral bioavailability. International Journal of Pharmaceutical Sciences and Nanotechnology. 2015; 8(4):1-8.

74. Thirupathi G, Swetha E and Narendar D. Role of isradipine loaded solid lipid nanoparticles in the pharmacodynamic effect of isradipine in rats. Drug res, 2017; 67(03):163-169.
5. Zara GP, Bargoni A, Cavalli R, et al. Pharmacokinetics and tissue distribution of idarubicin loaded solid lipid nanoparticles after duodenal administration to rats. J Pharm Sci2002; 91:1324-33.

76. Dudhipala, Narendar, Ahmed Adel Ali Youssef, and Nagaraj Banala. Colloidal lipid nanodispersion enriched hydrogel of antifungal agent for management of fungal infections: comparative in-vitro, ex-vivo and in-vivo evaluation for oral and topical application. Chemistry and Physics of Lipids 2020: 104981.

Sandeep V, Narendar D, Arjun N and Kishan V. Lacidipine loaded solid lipid nanoparticles for oral delivery: Preparation, characterization and In vivo evaluation. IJPSN, 2016; 9(6):352430

78. Paliwal R, Rai S, Vaidya B, et al. Effect of lipid core material on characteristics of solid lipid nanoparticles designed for ora lymphatic delivery. Nanomedicine: NBM 2009; 5:184-91.

79. Chalikwar SS, Belgamwar VS, Talele VR, Surana SJ, Patil MU. Formulation and evaluation of Nimodipine-loaded solid lipid nanoparticles delivered via lymphatic transport system.Colloids Surf B Biointerfaces. 2012; 97:109-16.

0. Dudhipala N, Veerabrahma K. Pharmacokinetic and pharmacodynamic studies of nisoldipine loaded solid lipid nanoparticles by central composite design. Drug Dev Ind Pharm. 2015. (doi:10.3109/03639045.2015.1024685).

81. Narendar D, Karthik Yadav J, Thirupathi G. Comparative study of nisoldipine-loaded nanostructured lipid carriers and solid lipid nanoparticles for oral delivery: preparation, characterization, permeation and pharmacokinetic evaluation. Artificial cells, nanomed and biotech. Early online 11 April, 2018, doi.org/10.1080/21691401.2018.1465068

82. Almeida AJ, Runge S, Muller RH. Peptide-loaded solid lipid nanoparticles (SLN): influence of production parameters. Int J Pharm 1997; 149:255-65.

3. Luo CF, Yuan M, Chen MS, et al. Pharmacokinetics, tissue distribution and relative bioavailability of puerarin solid lipid nanoparticles following oral administration. Int J Pharm 2011; 410:138-44

84. HouLi Li, XiaoBin Zhao, YuKun Ma, GuangXiZhai, LingBing Li, HongXiang Lou. Enhancement of gastrointestinal absorption of quercetin by solid lipid nanoparticles. Journal of Controlled Release. 2009; 133(3):238-244.

85. Pandey R, Sharma S, Khuller GK. Oral solid lipid nanoparticlebased antitubercular chemotherapy. Tuberculosis 2005; 85:41520.

86. Guguloth S, D. Narender and V. Kishan. Preparation, Characterization and In vivo Evaluation of Rosuvastatin Calcium Loaded Solid Lipid Nanoparticles. International Journal of Pharmaceutical Sciences and Nanotechnology, 2015; 8(1):27792785

87. Narendar D and Kishan V. Improved anti-hyperlipidemic activity of Rosuvastatin Calcium via lipid nanoparticles: pharmacokinetic and pharmacodynamic evaluation. Euro J Pharm Biopharm. 2017 110 (1):47-57.

88. Narendar D, Thirupathi G. Neuroprotective effect of ropinirole loaded lipid nanoparticles hydrogel for Parkinson's disease: preparation, in vitro, ex vivo, pharmacokinetic and pharmacodynamic evaluation. Pharmaceutics, 2020; 12(5):448.

9. Kushwaha AK, Vuddanda PR, Karunanidhi P, Singh SK, and Singh S. Development and Evaluation of Solid Lipid Nanoparticles of Raloxifene Hydrochloride for Enhanced Bioavailability. BioMed Research International Volume 2013 (2013), Article ID 584549, 1-

90. Tiwari R, Kamla Pathak. Nanostructured lipid carrier versus solid lipid nanoparticles of simvastatin: Comparative analysis of characteristics, pharmacokinetics and tissue uptake. International Journal of Pharmaceutics, Volume 2011; 415(1-2):232-243.

91. Cavalli R, Bargoni A, Podio V, et al. Duodenal administration of solid lipid nanoparticles loaded with different percentages of tobramycin. J Pharm Sci 2003; 92:1085-95.

92. Luo Y, Chen D, Ren L, et al. Solid lipid nanoparticles for enhancing vinpocetine's oral bioavailability. J Control Release 2006; 114:539

3. Narendar D and Karthik yadav J. Lipid nanoparticles of zaleplon for improved oral delivery by Box-Behnken design: Optimization, in vitro and in vivo evaluation. Drug Dev Ind Pharm, 2017; 43(7):1205-1214. 